\title{
ANÁLISE DO IMPACTO DA VARIABILIDADE DAS CHUVAS EM MUNICÍPIOS QUE PRODUZEM SOJA NO PARANÁ, BRASIL
}

\author{
Vinicius Carmello ${ }^{(a)}$ \\ (a) Geógrafo, Doutorando e Bolsista Fapesp (Processo número: 2014/01071-1). Departamento de \\ Geografia/Universidade Estadual Paulista - UNESP, Presidente Prudente. viniciuscarmello@gmail.com
}

Eixo: Climatologia em diferentes níveis escalares: mudanças e variabilidades

\section{Resumo}

O objetivo deste artigo é analisar o impacto da variabilidade das chuvas em três municípios produtores de soja do estado do Paraná, como contribuição aos estudos da relação entre clima e agricultura na escala regional de uma zona de transição climática entre as características tropicais e subtropicais. Para chegar aos resultados, foram coletados dados de precipitação diários $(\mathrm{mm})$ e representados em períodos anuais e decendiais. Foram coletados dados de produtividade agrícola por municípios representados em gráficos que mostram a variação total e também o desvio de produtividade. Concluiu-se que o perfil agrícola de Ibaiti, Ponta Grossa e Santo Inácio são distintos, mensuráveis segundo a relação entre a variação dos dados de chuva, com os dados de produtividade de soja. Observou-se queda da produtividade de soja em Santo Inácio ocasionado por um período de menor concentração de chuva em uma fase importante fenologicamente para a planta de soja. O mesmo ocorreu no posto pluviométrico de Ponta Grossa, entretanto, não houve a mesma resposta quanto à queda de produtividade.

Palavras chave: Chuva; Variabilidade; Brasil; Sul do Brasil; Agricultura

\section{1 . Introdução}

A relação de dependência entre clima e agricultura nos dias atuais é questionável, sobretudo pela grande inserção da técnica no campo, originárias de investimentos na ciência, na tecnologia e na inovação das formas de manejo das atividades do campo. Entretanto, cabe ressaltar que o acesso a estas inovações é desigual e contraditório, segundo os interesses diversos de agentes sociais que atuam no universo do campo.

Desigual, pois existem diferentes formas de conduzir as atividades no campo, e estas são consideradas diversas segundo as características socioeconômicas dos mais diversos territórios agrícolas. Na escala de municípios, por exemplo, segundo as características agrícolas apresentadas, há o desempenho de "papeis" distintos no âmbito do cenário agrícola na escala estadual. Isso remete a uma maior ou menor relação com a variabilidade climática. 
Neste artigo são discutidos alguns aspectos relacionados ao perfil agrícola do estado do Paraná assim

como o papel da soja neste contexto onde a economia esta baseada na produção de grãos. Buscou-se também desvelar teorias acerca das necessidades hídricas no campo e do clima como um dos fatores responsáveis pela organização agrícola em unidades produtoras de soja.

O objetivo deste artigo é analisar o impacto da variabilidade da chuva em três municípios produtores de soja do estado do Paraná, como contribuição aos estudos da relação entre clima e agricultura na escala regional de uma zona de transição climática entre o as características tropicais e subtropicais.

No que tange a estrutura do artigo, este divide-se em três partes, num primeiro momento, analisaram-se os totais anuais de chuva para verificar a variação anual, posteriormente, os dados de produtividade de soja e para finalizar, os acúmulos decendiais de chuva, assim como os resultados derivados da técnica de correlação estatística do coeficiente de Kendall, como contribuição a avaliação da relação entre chuva e produtividade da soja em três municípios do estado do Paraná.

\section{Procedimentos e técnicas}

Os dados de produção e de área plantada correspondem ao período de 1999-2010. Os dados de produtividade para cada município são definidos através da divisão entre a quantidade produzida e área destinada à cultura. Foi utilizada a técnica de agrupamento (ward) para dividir os 132 municípios em 3 Grupos de produtividade (P1, P2 e P3), em que se divide cada série em Quartis.

Com os três grupos definidos, foram selecionados um município representativo de cada grupo de produtividade. Ou seja, foi escolhido um município para representar o grupo de municípios do grupo P1 de alta produtividade (Ponta Grossa), de média produtividade (Ibaiti) e de baixa produtividade (Santo Inácio).

Estes grupos, assim como a localização dos três municípios podem ser observados na figura seguinte (Figura 1). Os dados de precipitação foram coletados de 03 posto pluviométricos representativos e instalados nos municípios de Santo Inácio, Ibaiti e Ponta Grossa (Fig. 1).

Estes postos derivam-se de uma rede de 89 postos pluviométricos. Os dados de precipitação foram representados na escala decendial para comparação com os períodos fenológicos da soja entre os meses de outubro a abril (ano agrícola). Essa organização auxiliou a avaliação quanto aos níveis de dependência da planta à variabilidade pluviométrica. 
Após a representação dos valores de produtividade e dos padrões de chuva em cada um dos três postos pluviométricos selecionados. Utilizou-se da técnica de correlação a partir do teste de Kendall no software XLStat1 e das séries históricas das duas variáveis

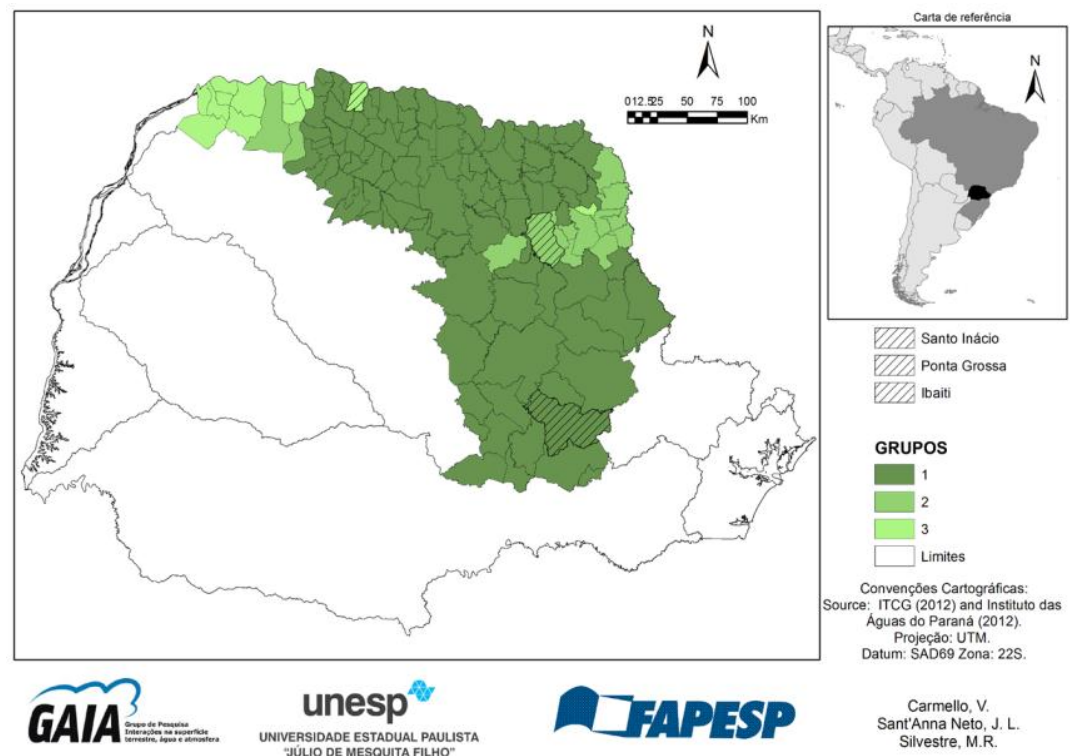

Figura 1. Mapa da área de estudos e os três municípios representativos que produzem soja Fonte: Carmello (2013); Carmello et al.(2014)

\section{Resultados e Discussão}

\subsection{O impacto da variabilidade das chuvas em Santo Inácio, Ibaiti e Ponta Grossa - Paraná, Brasil}

A variabilidade é, consoante Conti (2005) produto tanto do espaço quanto do tempo, ela envolve a atmosfera, oceano, superfícies sólidas, neve, gelo, etc., e sua atuação nunca é igual de um ano para o outro, e nem de década em décadas, pois são verificadas flutuações em curto, médio e longo prazo. Para Sant'Anna Neto e Zavattini (2000) apud Carmello et.al. (2013), são flutuações climáticas que dependendo da escala temporal podem caracterizar uma mudança climática ou apenas uma variabilidade - ciclos periódicos que tendem a se repetir de tempos em tempos.

Estas flutuações contínuas, associadas em sua maioria com mecanismos distintos de produção da precipitação, interferem diretamente no papel das chuvas na obtenção de água pelas plantas. Tais

1 A licença do software está em nome de Lindberg Júnior, discente de doutorado e integrante do laboratório GAIA, UNESP. 
XVII Simpósio Brasileiro

de Geografia Fisica Aplicada

I Congresso Nacional

de Geografia Física
OS DESAFIOS DA GEOGRAFIA FÍSICA NA FRONTEIRA DO CONHECIMENTO

Instituto de Geociências - Unicamp

Campinas - SP

28 de Junho à 02 de Julho de 2017

variações nos padrões de precipitação desencadeiam períodos ora de baixa, ora de alta pluviosidade e, ocasionam períodos curtos, médios e longos de estiagens.

Para atingir o objetivo deste trabalho e em relação à variabilidade das chuvas em período de safra agrícola da soja, foram realizadas coletas de dados de chuvas para um período de 10 safras agrícolas da soja em 132 municípios do estado do Paraná para compor uma avaliação ampla do território da soja no Paraná. Entretanto, neste artigo são abordados resultados concluídos em três deles: Santo Inácio, Ibaiti e Ponta Grossa.

Verifica-se que o posto pluviométrico localizado no município de Ibaiti apresenta registrou valores cujo percentil mostrou serem extremamente secos em 1999/00, 2001/02, 2003/04 e 2004/05. Em Ponta Grossa, os valores mais baixos de precipitação ocorreram em 2001/02, 2005/06 e 2008/09, já em Santo Inácio, houve dois anos que mostraram valores secos, em 1999/00 e 2005/06 (Quadro 1).

Estes resultados seguem uma análise mais ampla onde foram analisados 89 postos pluviométricos em que foi definido o de 1999/00 como padrão seco, e 2009/10 como padrão chuvoso.

Quadro 1. Distribuição dos totais anuais de chuva $(\mathrm{mm})$ em postos pluviométricos de Ibaiti, Ponta Grossa e Santo Inácio

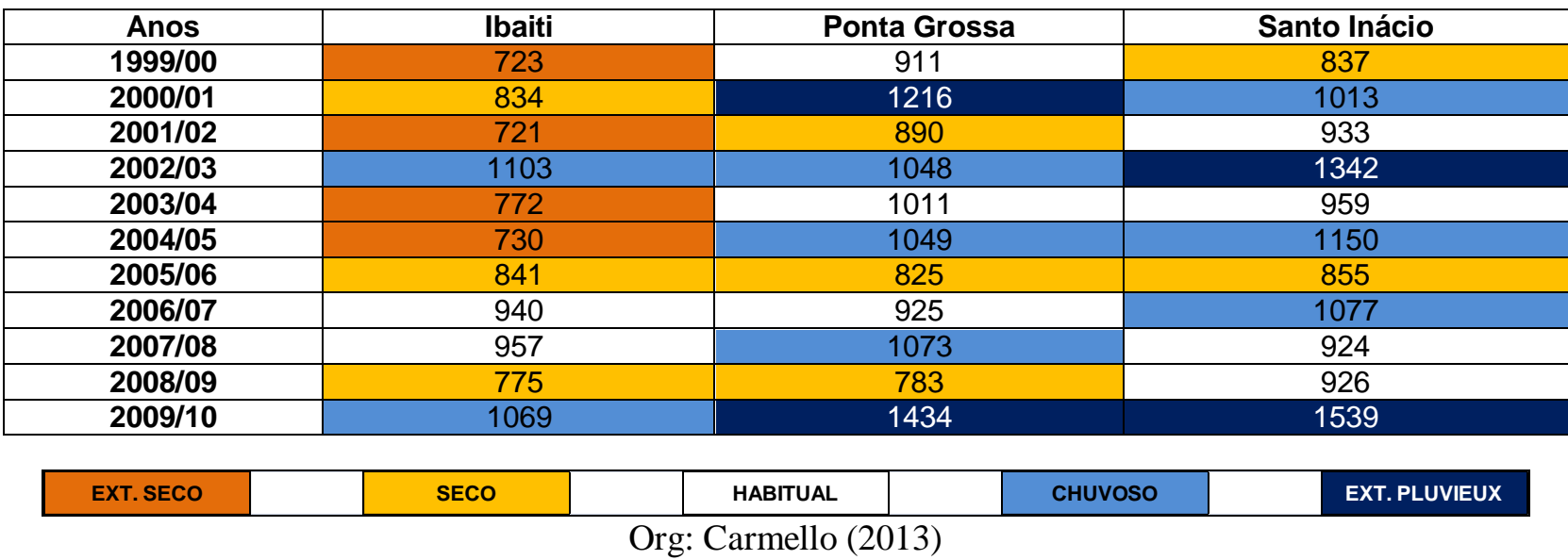

Para medir o impacto da variabilidade das chuvas em municípios produtores de soja no Paraná, busca-se apresentar os dados de produtividade de soja em um recorte temporal de 11 safras: 1999/00 até 2009/10. Estes dados foram coletados junto a Secretária Estadual de Agricultura e Abastecimento do estado do Paraná, secretária de Londrina. Os dados agrícolas, a princípio, são disponibilizados apenas representando a produção anual total por município, e para se chegar ao valor de produtividade (Figura 2), divide-se a produção em kg pelo hectare $(\mathrm{Kg} / \mathrm{ha})$. 


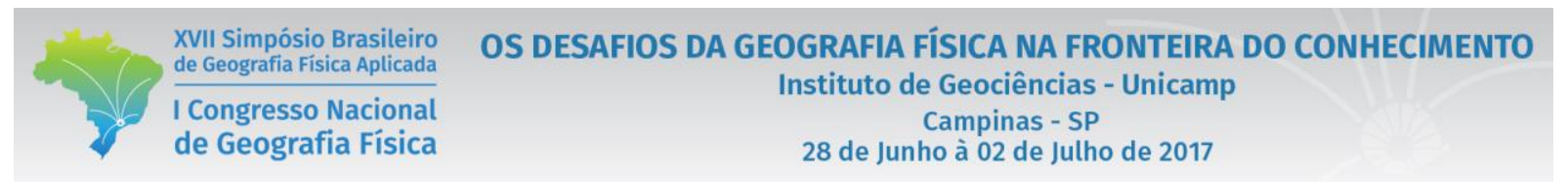

Com isso atingiu-se os resultados seguintes: Ibaiti não apresentou registros de produção de soja em 1999/00 e 2000/01, já Santo Inácio, em 2009/10. Ponta Grossa se destaca pelo desempenho expressivo em toda série histórica analisada. Segundo o desvio de produtividade (Figura 3), a maior variação foi em 2003/04 em dados registrados em Santo Inácio. Buscar-se-ão nos registros de chuva respostas a esta variação.

Cada um deles apresentam características agrícolas distintas com reflexos nos resultados finais de produtividade da soja. Esta relação esta associada ao nível tecnológico de cada um destes municípios de são diferentes conforme seus contextos históricos de colonização e estruturação econômica, política, social e econômica. Com isso, a correlação entre totais de precipitação versus produtividade se diferem, justamente porque existe a variável tecnológica envolvida.

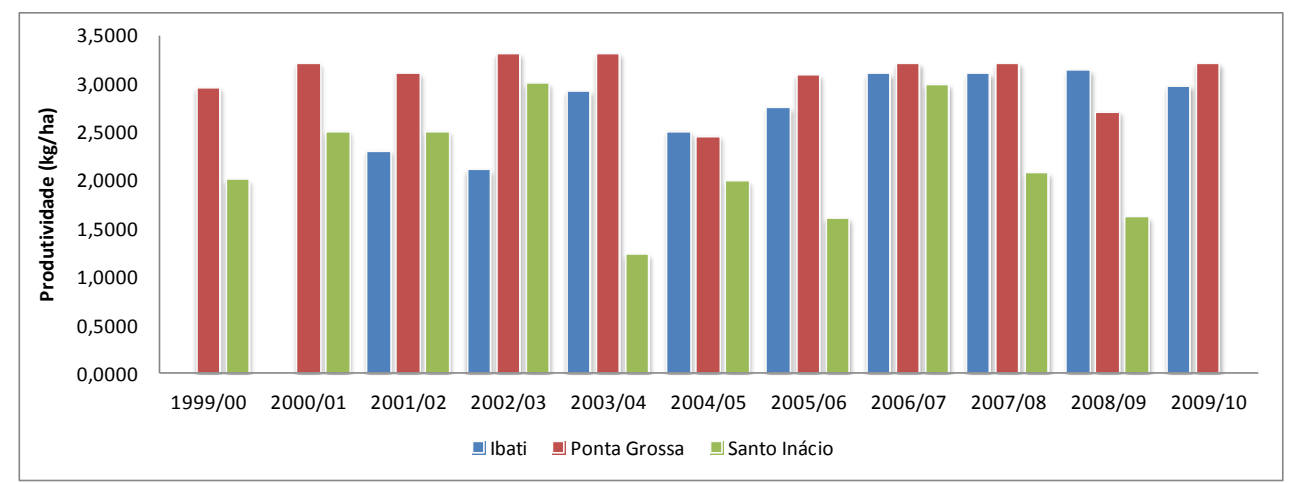

Figura 2. Total da produtividade anual de soja nos municípios de Ibaiti, Ponta Grossa e Santo Inácio. Período: 1999 - 2000 a 2009 - 2010. Fonte de dados: SEAB, 2011. Org.: Carmello (2013)

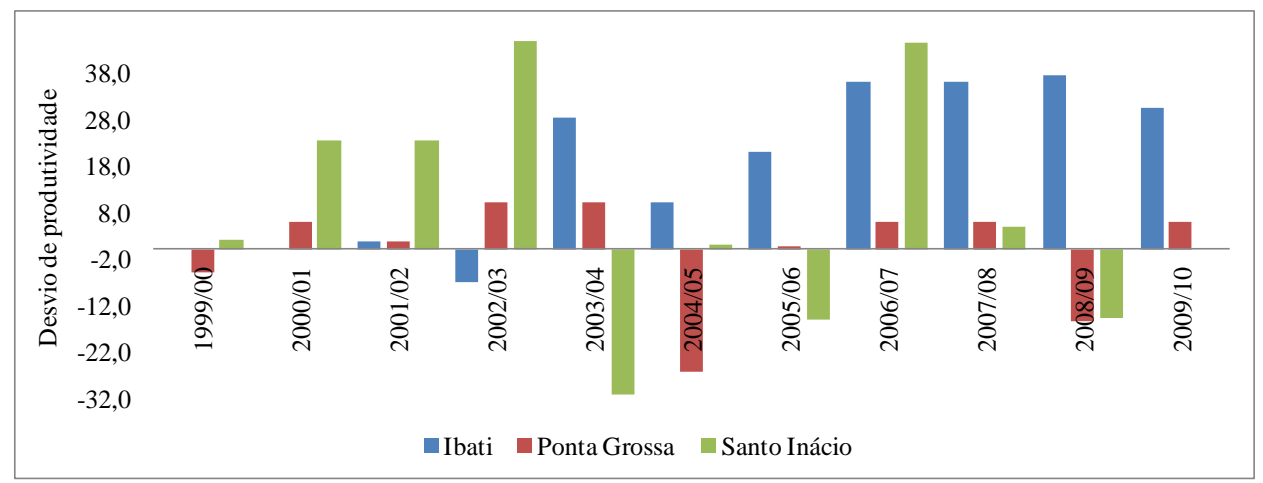

Figura 3. Desvio de produtividade anual de soja nos municípios de Ibaiti, Ponta Grossa e Santo Inácio. Período: 1999 - 2000 a 2009 - 2010. Fonte de dados: SEAB, 2011. Org.: Carmello (2013) 


\section{OS DESAFIOS DA GEOGRAFIA FÍSICA NA FRONTEIRA DO CONHECIMENTO \\ Instituto de Geociências - Unicamp \\ Campinas - SP \\ 28 de Junho à 02 de Julho de 2017}

Para reduzir a escala de análise da distribuição das chuvas e consequentemente, aproximar a variáveis, foi representado o acúmulo decendial das chuvas registrados em três postos pluviométricos: Ibaiti, Ponta Grossa e Santo Inácio; agrupados segundo a técnica do percentil com resultados que mostram períodos extremamente secos, secos, habituais, chuvosos e extremamente chuvosos (Figura 4).

O intuito é realizar um comparativo com o calendário fisiológico da cultura da soja, destacando o período crítico para o desenvolvimento fisiológico e, assim, observar se houveram fases inapropriadas para o desenvolvimento da cultura, sobretudo, no período crítico e se são esses os fatores responsáveis pela diminuição da produtividade agrícola nos anos padrões e no ano com a maior variação. Em 2003/04 é possível observar no mês de janeiro, um decêndio extremamente seco registrado nos três postos pluviométricos.

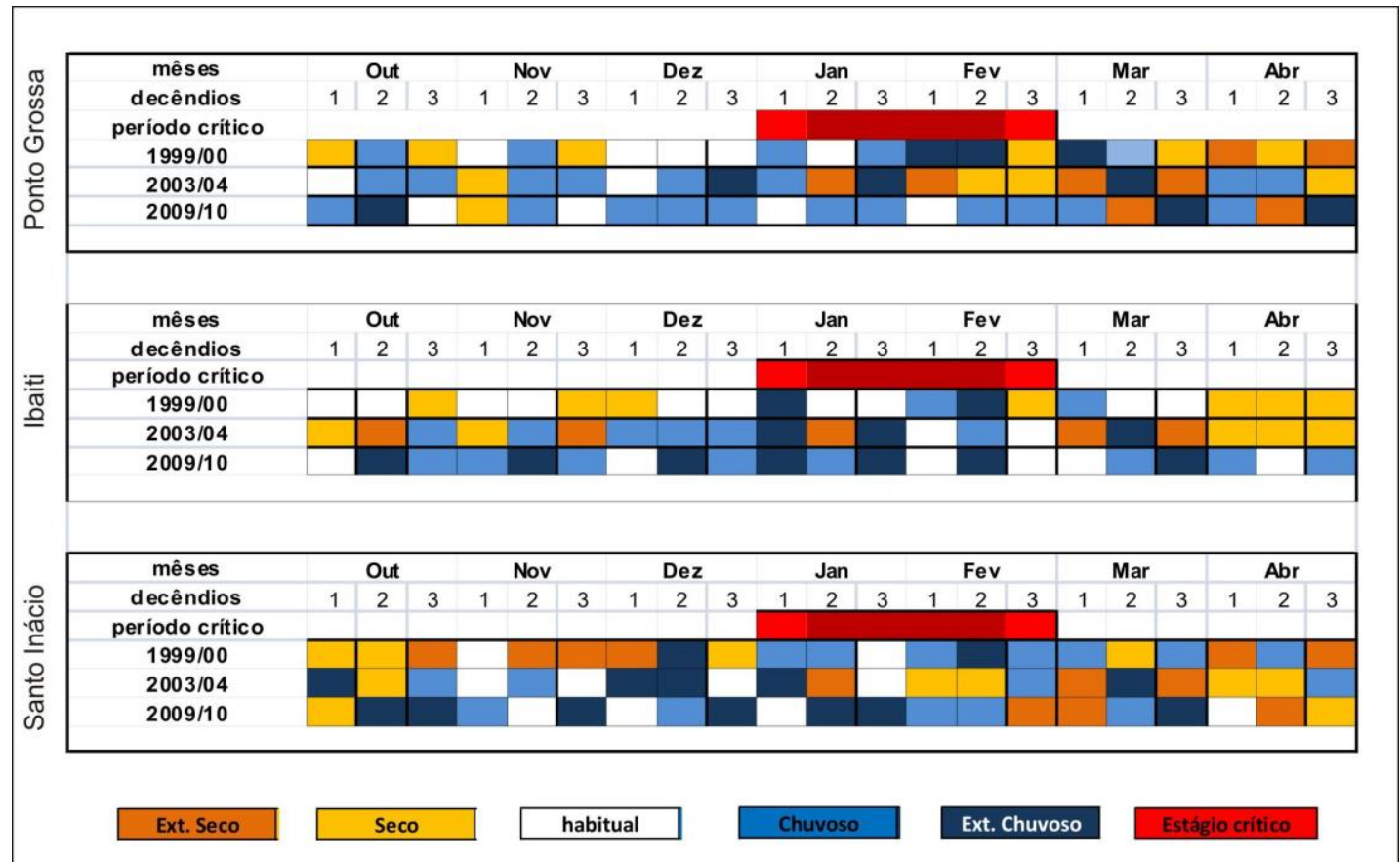

Figura 4. Distribuição decendial das chuvas para os municípios de Ponta Grossa, Ibaiti e Santo Inácio em relação ao período crítico da soja segundo calendário agrícola.

Fonte: Carmello (2013)

Sabe-se que estiagens nos meses de janeiro a março são frequentes no estado do Paraná e, geralmente, coincidem com o período crítico das culturas de verão (floração e enchimento de grãos). Esse período tem sido apontado como fator limitante ao rendimento da soja (BERLATO e FONTANA, 1999; MATZENAUER et al. 2003). Analisando os decêndios do ano agrícola de 1999/00, notam-se períodos cujos registros de chuva mostraram valores considerados secos e extremamente secos nos meses de outubro, novembro, março e abril dos três postos. Os decêndios chuvosos foram nos meses de janeiro e fevereiro, nos três pontos (Figura 3). 
Os dados de chuva do ano agrícola padrão de 2009/10 mostram períodos secos e extremamente secos em decêndios dos meses de fevereiro, março e abril nos postos de Ponta Grossa e Santo Inácio. Os registros do posto pluviométrico localizado no município de Ibaiti mostram decêndios chuvosos e extremamente chuvosos.

Em Santo Inácio, foi registrado um decêndio extremamente chuvoso em janeiro de 2004 e dois secos em fevereiro do mesmo ano. Isto se repete nos registros de Ponta Grossa: o segundo decêndio de janeiro de 2003, extremamente seco, intercalado por dois chuvosos.

O desvio de produtividade de soja registrado em 2003/04 por Santo Inácio (Figura 3) pode estar associado a estes decêndios extremamente secos e secos ocorridos em janeiro e fevereiro de 2004 (importante período para o desenvolvimento da planta de soja).

Abaixo, segue quadro síntese das correlações estatísticas entre as variáveis: chuva e soja, a partir do teste de coeficiente de Kendall para os três municípios, foi utilizado o software XLStat ${ }^{\circledR}$ e descrito nos procedimentos metodológicos.

O coeficiente de correlação linear refere-se a um procedimento numérico entre as variáveis, e não implica numa relação de causa e efeito, mas como medida da intensidade de um relacionamento linear entre as duas variáveis (ANDRIOTTI, 2004). A vantagem sobre os coeficientes de Kendall, é que esse teste trata os valores diretos da série, não dos seus respectivos ranks1. Isso refletirá em uma relação mais estreita entre duas variáveis, caso exista (FALCÃO, 2012).

Porém, os resultados ora apresentados não são estatisticamente significativos, pois os coeficientes de determinação mostram uma correlação, entre $2.2 \%$ a $12.3 \%$, e consequentemente, pouca relação estatisticamente significativa nestes municípios analisados.

Tabela 1. Resultados de correlação a partir do coeficiente de Kendall

\begin{tabular}{lccc}
\hline \multicolumn{1}{c}{ Município } & $\begin{array}{c}\text { Coeficiente de } \\
\text { correlação Kendall }\end{array}$ & *p-valor & $\begin{array}{c}\text { Coeficiente de } \\
\text { determinação } \\
\text { Kendall \% }\end{array}$ \\
\hline Ibaiti & 0,241 & 0,058 & 5,8 \\
Ponta Grossa & 0,350 & 0,123 & 12,3 \\
Santo Inácio & 0,147 & 0,022 & 2,2 \\
\hline
\end{tabular}

*os resultados estatisticamente significativos são aqueles cujo p-valor está abaixo de 0.05 


\section{Conclusão}

O papel da cultura da soja é expressivo no estado do Paraná e vêm ao longo dos últimos 40 anos, influenciando as estratégias do Estado para aperfeiçoar e aumentar sua abrangência, não só territorial, mas de rentabilidade, materializada na maior produtividade por hectare. Isto reflete diretamente nos interesses quanto aos níveis de dependência da agricultura perante as adversidades climáticas, diminuídos ao longo do tempo, principalmente pelo desenvolvimento tecnológico aplicado no campo, mesmo que de forma contraditória entre quem possui acesso a estas inovações e adaptações.

Essa tendência acompanha padrões internacionais que vem ao longo das últimas décadas elaborando políticas voltadas à produção de grãos voltada à exportação. O estado do Paraná segue essa tendência global e vem aplicando técnicas que estão favorecendo o aumento da produtividade agrícola e a diminuição da dependência aos episódios adversos do tempo atmosférico. Entretanto, no contexto brasileiro, nem todos possuem o mesmo acesso a este tipo de inovação tecnológica, ou seja, ainda existem regiões que produzem soja, mas que conduzem suas atividades agrícolas baseadas em um outro tempo, um tempo mais remoto e precário.

Houveram variações, tanto dos registros de produtividade de soja, quanto dos de precipitação pluviométrica em Ibaiti, Ponta Grossa e Santo Inácio. Isto fica evidente no ano de 2003/04, sobretudo em Santo Inácio e de menor proporção em Ibaiti e Ponta Grossa. Houve decêndios com diminuição da chuva em janeiro e fevereiro de 2004, tanto em Santo Inácio, quanto em Ponta Grossa, porém a variação da produtividade é registrada no município de Santo Inácio.

Em relação aos resultados de correlação estatística, estes não mostram dependência significativa entre as variáveis total de chuva e total de produtividade, mostrando assim, a importância de se reduzir a escala de análise, sobretudo dos totais de chuva, e comparar com os principais estágios críticos da soja.

Na pesquisa de mestrado desenvolvida pelo autor (CARMELLO, 2013), são encontrados dados derivados do Senso agropecuário de 2006, onde é possível notar diferenças no perfil agrícola dos três municípios. Ibaiti, Ponta Grossa e Santo Inácio foram determinadas para representar três regiões de produtividade de soja distintas (baixa média e alta produtividade). Com esses resultados, observou-se que os municípios se diferenciam com forte influência do total da área em que ocupam e, consequentemente, do total que destinam para a agricultura e para a soja. Há diferenças no que tange os investimentos e em reformas e benfeitorias nos estabelecimentos, assim como, no total de pessoas que trabalham ou atuam diretamente em atividades agrícolas. Isto reflete no grau de dependência e vulnerabilidade social-agrícola na escala do município. 


\section{Bibliografia}

ANDRIOTTI, J.L.S. Fundamentos de estatística e geoestatística. São Leopoldo: Unisinos, 2004.

ASSUNÇÃO, W. L. Climatologia da cafeicultura irrigada no município de Araguari (MG). Presidente Prudente. 2002. 178p. Tese (Doutorado em Geografia). Faculdade de Ciências e Tecnologia, Universidade Estadual Paulista, Presidente Prudente.

AWAD, M; CASTRO, P. R. C. Introdução à fisiologia vegetal. São Paulo: Nobel, 1989

AYOADE, J. O. Introdução a Climatologia para os Trópicos. São Paulo: Ed. Bertrand. Brasil. 1983

BERLATO, M. A.; FONTANA, D. C. Variabilidade interanual da precipitação pluvial e rendimento da soja no Estado do Rio Grande do Sul. Revista Brasileira de Agrometeorologia, Santa Maria, v.7, n. 1, 1999.

CAMPOS, M. C. A Embrapa/Soja em Londrina-PR a pesquisa agrícola de um país moderno. 2011. 120p. Tese (Doutorado em Geografia) - Universidade Federal de Santa Catarina, Florianópolis.

Carmello, Vinicius; Silvestre, Miriam Rodrigues; Sant'Anna Neto, João Lima. Desigualdade no campo e o risco climático em áreas de produção da soja no sul do Brasil

CARMELLO, V. análise da área plantada em relação à produção da soja em cinco municípios da região metropolitana de Londrina - PR. CAMINHOS DE GEOGRAFIA - revista online, Uberlândia v. 13, n. 42, 2012.

CARMELLO, V. Análise da variabilidade das chuvas e sua relação com a produtividade da soja na vertente paranaense da bacia do rio Paranapanema. 123p. Dissertação (mestrado em geografia). Faculdade de Ciência e Tecnologia - UNESP. Presidente Prudente, 2013.

CARMELLO, V; SILVESTRE, M. R; DUBREUIL, V; SANT'ANNA NETO, J. L. Chuva, Soja e Risco agrícola na Vertente Sul da Bacia do Rio Paranapanema Paraná. In: Simpósio brasileiro de geografia física aplicada, XV, Vitória: Anais... 2013, p. 289-297.

CARMELLO, V.; SILVESTRE, M. R.; SANT'ANNA NETO, J. L. Desigualdade no campo e o risco climático em áreas de produção da soja no sul do Brasil. In: Multidimensão e territórios de risco. Imprensa da Universidade de Coimbra, Guimarães, 2014.

CONTI, J. B. Considerações sobre as mudanças climáticas globais. Revista do Departamento de Geografia, São Paulo, v. 16, 2005.

DIAS, M. A. F. S; SILVA, M, G, A, J. Para entender tempo e clima. In: SILVA, M. G. A. J; DIAS, M. A. F. S (Org.). Tempo e clima no Brasil. São Paulo: Oficina de Textos. 2009.

ELY, D. F.; ALMEIDA, I. R. de; SANT'ANNA NETO, J. L. Implicações Políticas e econômicas e variabilidade climática no rendimento da cultura do milho no estado do Paraná. In: Revista do Departamento de Geociências, Londrina: UEL. Londrina, v. 12, n. 1, 2003.

FALCÃO, A. J. T. Detecção de Correlação e Causalidade em séries temporais não categóricas. 2012. $83 \mathrm{f}$. (Mestrado em Engenharia Informática). Faculdade de Ciência e Tecnologia - Universidade Nova de Lisboa. Lisboa.

FINA, A. L; RAVELO, A. C. Climatologia y Fenologia Agrícolas, Buenos Aires: EUDEBA, 1973.

MATZENAUER. R; BERNI, N. A; MALUF, J. R. T. Estimativa do consumo relativo de água para a cultura da soja no Estado do Rio Grande do Sul. Ciência Rural, Santa Maria, v. 33, n. 6, 2003.

MOTA, F. S.; AGENDES, M. O. O. Clima e Agricultura no Brasil. Porto Alegre: Sagra, 1986.

ROESSING, A. C.; LAZZAROTTO, J. J. A criação de empregos pelo complexo agroindustrial da soja. In: Reunião de pesquisa de soja na região central do Brasil. Ribeirão Preto. Resumos... Londrina: Embrapa Soja: Fundação Meridional, 2004.

SANT'ANNA NETO, J. L; ZAVATINI, J. A. Variabilidade e mudanças climáticas: implicações ambientais e socioeconômicas. Maringá: UEM, 2000. 